\title{
The relationship between mental health and health- related physical fitness of university students
}

\author{
Bog Ja Jeoung ${ }^{1}$, Myoung-Sun Hong ${ }^{2}$, Yang Chool Lee ${ }^{3, *}$ \\ 'Department of Exercise Rehabilitation \&Welfare, Gachon University, Inchon, Korea \\ ${ }^{2}$ Department of Health Care Management, Gachon University, Seongnam, Korea \\ ${ }^{3}$ Department of Sports \& Leisure Studies, Gachon University, Seongnam, Korea
}

The purpose of this study was to examine the relationship between mental health and health-related physical fitness of university students. For this study, 228 university students were participated in this experiment (male 91, female 137). We tested health-related physical fitness and mental health with questionnaire. Data were analyzed using independent t-test and liner regression. In the present results, there was significant difference according to gender in mental health and health-related physical fitness. The correlation between physical fitness and mental health was also observed.

Keywords: University student, Mental health, Physical fitness

\section{INTRODUCTION}

As university students take their first steps as adults after exiting adolescence, they adapt to a diverse environment, expanded personal relationships, scholastic tests that are different from those of the past middle and high school years, autonomy, and a transition period between heteronomy (Han and Lee, 2006). During the middle and high school years, their education focuses on college entrance exams and their physical education is low because of increased study. Additionally, their use of leisure time is inefficient because of the absence of physical activity; as a result, university students' physical fitness levels are low. Low physical fitness levels decrease activities of daily living and lead to stress and unhealthy lifestyles, lowering the level of satisfaction in mental health and life (Hunt and Eisenberg, 2010; Moon, 2008; Zivin el al., 2009). Participation in physical activity and sports during school days leads to continuous exercise participation after adulthood and contributes to preventing obesity and adult disease (Han and Lee, 2006; Han et al., 2009). Therefore, participation in physical activities and sports in university life is very important, as are the maintenance and promotion of physical fitness.

Earlier studies reported a significant correlation between physical fitness and mental health (Labrie et al., 2010). Regular physical activity and participation in sports decrease anxiety and depression and increase self-esteem (Bolognini et al., 1996); cardiopulmonary fitness and muscle endurance decrease the risk of obesity and metabolic syndrome (Dubos et al., 2007; Kim et al., 2012; LaMote et al., 2005). Research related to physical fitness and mental health focused on the effect of exercise and research with elementary, middle, and high school students as subjects (Han et al., 2009; Ryu, 1995; Han et al., 2006; Jin, 2010) but there has been little research on the correlation between physical fitness and mental health with university students as subjects. Therefore, this research aimed to identify the correlation between the physical fitness and mental health of college students.

\section{MATERIALS AND METHODS}

\section{Participants}

After explaining the purpose of the research to the university
${ }^{*}$ Corresponding author: Yang Chool Lee

Department of Sports \& Leisure Studies, Gachon University,

1342 Seongnam-daero, Sujeong-gu, Seongnam 461-701, Korea

Tel: +82-32-820-4354, Fax: +82-32-820-4049, E-mail: yclee@gachon.ac.kr

Received: November 18, 2013/ Accepted: December 18, 2013
This is an Open Access article distributed under the terms of the Creative Commons Attribution Non-Commercial License (http://creativecommons.org/licenses/by-nc/3.0/) which permits unrestricted non-commercial use, distribution, and reproduction in any medium, provided the original work is properly cited. 
Table 1. Demographic characteristics of the participants $(n=228)$

\begin{tabular}{llc}
\hline Item & & $\mathrm{n}(\%)$ \\
\hline Gender & Male & $91(39.9)$ \\
& Female & $137(60.1)$ \\
Regular exercise participated & Yes & $118(51.8)$ \\
& No & $110(48.2)$ \\
Drinking & Yes & $55(24.1)$ \\
& No & $173(75.9)$ \\
Smoking & Yes & $16(7)$ \\
& No & $212(93)$ \\
Grade of undergraduate & Freshman & $60(26.3)$ \\
& Sophomore & $52(22.8)$ \\
& Junior & $73(32)$ \\
& Senior & $43(18.9)$ \\
\hline
\end{tabular}

students attending a university in I city, 228 college students who wished to participate in this research were randomly selected to participate in questionnaires, a mental health test, and health-related physical fitness test. The patients' general characteristics are shown in Table 1.

\section{Testing procedure and method}

The mental health test used in this research consisted of 47 mental health questions designed by Lee (1985) to create a factor analysis. This was based on the translated version of a test suited for the state of affairs in Korea that had 90 questions (List-90-Revision) developed by Derogatis et al. (1976). The scale of this test is composed of the five Likert scale stages (1, strongly disagree; 5, strongly agree), while the nine subfactors are composed of six questions on somatization, five questions on obsession, eight questions on interpersonal sensibility, four questions on depression, five questions on anxiety, six questions on hostility, four questions on phobia, four questions on paranoia, and four questions on psychosis. The lower the score earned in each field, the better the patient's mental health state.

\section{Health-related physical fitness}

\section{Progressive aerobic cardiovascular endurance run (PACER)-20 m}

The cardiopulmonary endurance test used in this research measured the PACER $20 \mathrm{~m}$ shuttle run. The research subjects at the starting point start running forward in the $20 \mathrm{~m}$ at the music and mid-low-pitched sound; before the next mid-low-pitched sound starts, they have to locate themselves in the starting point in the opposite direction and run when the mid-low-pitched sound starts.

\section{Strength-grip}

The active force generation test measures an individual's maxi- mum strength. Sthenometry was conducted by measuring the squeeze strength. The digital squeeze dynamometer (TKK, Japan) adjusts the width customized for the subject's hand (the second knuckle of the middle finger should grab the finger stop in the right location); after gripping, he or she was encouraged to pull it with all of their strength. The measurement was carried out twice for each hand and the highest figure was recorded.

\section{Endurance strength - sit-ups}

Muscle endurance is how long a muscle can generate strength, and the muscle endurance test used in this research consisted of a sit-up test, an item in the fitness test. The implementation method for sit-ups consists of the following: after the subject lies down on the mat, knees are bent, the upper body rolls up, and both hands touch the knees while atop the fore thighs. The first exercise is carried out while matching the mid- to low-pitched sound at 3-s intervals and the number of times is recorded until he or she cannot do two sit-ups in 3-sec intervals.

\section{Endurance strength - push-ups}

For push-ups, male students kept their legs straight and female students put their knees on the ground. After placing both arms shoulder width apart, the arms were brought straight out from the head to the shoulders, back, waist, buttock, and knees; in the case of female students, the arms were placed into a $\Pi$ shape. The angle of the elbow was $90^{\circ}$, while the position from the head to the shoulders, back, waist, buttocks, and knees was maintained identical to the ready position. The push-ups lasted 2 sec each and the maximum push-ups by each subject were recorded.

\section{Flexibility - sit reach}

The left anteflexion measures the flexibility of the lumbus, so the bare feet touched the measurement tool completely, the upper body was slowly bent forward after straightening both feet, and flexibility was measured by pushing the measurement tool instrument with the middle fingers of both hands. During the measurement, the examiner pushed the subject's knees so that they did not bend. The examination starting number of the left anteflexion was $-20 \mathrm{~cm}$.

\section{Body composition}

The degree of obesity was determined by calculating the weight $(\mathrm{kg})$ divided by height $\left(\mathrm{m}^{2}\right)$ through the body mass index (BMI) method. 


\section{Data analysis}

Following the purpose of this research, a statistical analysis was carried out by using the SPSS for Windows program. A test was implemented to find the difference according to gender, while the linear regression method was used to identify the correlation between health-related physical fitness and mental health. The statistical level of significance was $P<0.05$.

\section{RESULTS}

\section{Mental health and health-related physical fitness by gender}

After analyzing the college students' health-related physical fitness and mental health according to gender on mental health and the subdomains of mental health including hostility, anxiety, and obsession, it appeared that the female students scored higher than the male students and that the difference was statistically significant. Moreover, regarding health-related physical fitness, the male

Table 2. Difference of mental health according to gender

\begin{tabular}{lcccl}
\hline Item & $\begin{array}{c}\text { Male } \\
(\mathrm{n}=91)\end{array}$ & $\begin{array}{c}\text { Female } \\
(\mathrm{n}=137)\end{array}$ & $\mathrm{t}$ & $P$ \\
\hline Mental health & $69.61 \pm 22.1$ & $80.05 \pm 24.4$ & -3.27 & $0.001^{* *}$ \\
Psychosis & $6.89 \pm 3.1$ & $7.18 \pm 3.1$ & -0.707 & 0.480 \\
Paranoia & $6.75 \pm 3.01$ & $6.94 \pm 2.8$ & -0.461 & 0.645 \\
Phobia & $6.2 \pm 2.3$ & $6.19 \pm 2.4$ & 0.036 & 0.972 \\
Hostility & $5.63 \pm 1.9$ & $6.45 \pm 2.4$ & -2.71 & $0.007^{*}$ \\
Anxiety & $12.08 \pm 4.2$ & $14.9 \pm 5.1$ & -4.30 & $0.000^{* *}$ \\
Depression & $8.92 \pm 3.9$ & $9.91 \pm 3.8$ & -1.90 & 0.058 \\
Interpersonal sensibility & $16.01 \pm 6.2$ & $17.51 \pm 6.1$ & -1.8 & 0.073 \\
Obsessive compulsive & $10.7 \pm 3.8$ & $12.4 \pm 3.9$ & -3.27 & $0.001^{* *}$ \\
Somatization & $10.02 \pm 3.7$ & $12.44 \pm 3.9$ & -4.66 & $0.000^{* *}$ \\
\hline
\end{tabular}

${ }^{*}$ Represents $P<0.01$. ${ }^{* *}$ Represents $P<0.001$.

Table 3. Relationship between cardio pulmonary endurance and mental health

\begin{tabular}{lccccc}
\hline & \multicolumn{5}{c}{ Cardiovascular endurance (20 m run) } \\
\cline { 2 - 6 } & $\mathrm{b}$ & $\beta$ & $\mathrm{t}$ & $P$ & $\mathrm{R}^{2}$ \\
\hline Somatization & 1.23 & 0.178 & 1.58 & 0.114 & 0.115 \\
Psychosis & 0.69 & 0.094 & 0.820 & 0.413 & \\
Paranoia & 1.51 & 0.170 & 1.93 & 0.054 & \\
Phobia & 0.887 & 0.093 & 0.876 & 0.382 & \\
Hostility & -2.14 & -0.495 & -3.176 & $0.002^{* *}$ & \\
Anxiety & 0.386 & 0.069 & 0.603 & 0.547 & \\
Depression & 0.456 & 0.131 & 0.841 & 0.402 & \\
Interpersonal sensibility & -0.587 & -0.107 & -0.974 & 0.331 & \\
Obsessive compulsive & -1.11 & -0.220 & -2.15 & $0.032^{*}$ &
\end{tabular}

${ }^{*}$ Represents $P<0.05$. ${ }^{*}$ Represents $P<0.01$. students scored higher than the female students in cardiopulmonary endurance (shuttle run), muscle endurance (push-ups, sit-ups) and muscular strength (grip strength), the difference of which was statistically significant (Table 2).

\section{Correlation between health-related physical fitness and mental health}

Regression analysis performed to determine the influence of health-related physical fitness factor on mental health in college students revealed that cardiopulmonary endurance (shuttle run), a health-related physical fitness factor, influences hostility and obsession, subdomains of mental health (Table 3) and showed a statistically significant difference. This study demonstrated that the push-up muscle endurance test influenced interpersonal sensitivity, a subdomain of mental health (Table 4). Furthermore, sit-ups affect paranoia and hostility, also subdomains of mental health (Table 5). Muscular strength (grip strength) has an effect on the subdomains of mental health such as paranoia, hostility, and ob-

Table 4. Relationship between push-up and mental health

\begin{tabular}{lccccc}
\hline & \multicolumn{5}{c}{ Strength endurance (push-up) } \\
\cline { 2 - 6 } & $\mathrm{b}$ & $\beta$ & $\mathrm{t}$ & $P$ & $\mathrm{R}^{2}$ \\
\hline Somatization & 1.3 & 0.284 & 2.52 & $0.012^{*}$ & 0.103 \\
Psychosis & 0.735 & 0.151 & 1.31 & 0.191 & \\
Paranoia & 0.730 & 0.124 & 1.40 & 0.163 & \\
Phobia & 0.213 & 0.034 & 0.316 & 0.752 & \\
Hostility & -0.657 & -0.231 & -1.47 & 0.143 & \\
Anxiety & 0.083 & 0.022 & 0.195 & 0.846 & \\
Depression & -0.176 & -0.076 & -0.488 & 0.626 & \\
Interpersonal sensibility & -1.17 & -0.326 & -2.95 & $0.003^{* *}$ & \\
Obsessive compulsive & -0.36 & -0.108 & -1.08 & 0.280 & \\
\hline
\end{tabular}

*Represents $P<0.05$. * Represents $P<0.01$.

Table 5. Relationship between sit-up and mental health

\begin{tabular}{lccccc}
\hline & \multicolumn{5}{c}{ Strength endurance (sit-up) } \\
\cline { 2 - 6 } & $\mathrm{b}$ & $\beta$ & $\mathrm{t}$ & $\mathrm{c}$ & $\mathrm{R}^{2}$ \\
\hline Somatization & 2.02 & 0.287 & 2.58 & $0.010^{*}$ & 0.125 \\
Psychosis & 0.330 & 0.044 & 0.387 & 0.699 & \\
Paranoia & 2.17 & 0.238 & 2.73 & $0.007^{*}$ & \\
Phobia & 0.481 & 0.050 & 0.471 & 0.638 & \\
Hostility & -2.34 & -0.535 & -3.45 & $0.001^{* *}$ & \\
Anxiety & -0.635 & -0.112 & -0.985 & 0.326 & \\
Depression & 0.144 & 0.041 & 0.263 & 0.792 & \\
Interpersonal sensibility & -0.632 & -0.114 & -1.04 & 0.299 & \\
Obsessive compulsive & -0.083 & -0.016 & -0.164 & 0.870 & \\
\hline
\end{tabular}

*Represents $P<0.01$. **Represents $P<0.001$. 
Table 6. Relationship between grip strength and mental health

\begin{tabular}{lccccc}
\hline & \multicolumn{5}{c}{ Strength (grip-strength) } \\
\cline { 2 - 6 } & $\mathrm{b}$ & $\beta$ & $\mathrm{t}$ & \multicolumn{1}{c}{$P$} & $\mathrm{R}^{2}$ \\
\hline Somatization & 0.833 & 0.233 & 2.16 & $0.032^{*}$ & 0.177 \\
Psychosis & 0.541 & 0.142 & 1.29 & 0.198 & \\
Paranoia & 1.015 & 0.220 & 2.60 & $0.010^{* *}$ & \\
Phobia & -0.266 & -0.054 & -0.53 & 0.597 & \\
Hostility & -0.881 & -0.397 & -2.64 & $0.009^{* *}$ & \\
Anxiety & 0.112 & 0.039 & 0.352 & 0.725 & \\
Depression & -0.028 & -0.016 & -0.106 & 0.916 & \\
Interpersonal sensibility & -0.473 & -0.168 & -1.58 & 0.114 & \\
Obsessive compulsive & -0.587 & -0.226 & -2.35 & $0.020^{*}$ & \\
\hline
\end{tabular}

${ }^{*}$ Represents $P<0.05$. **Represents $P<0.01$.

Table 7. Relationship between sit-reaches and mental health

\begin{tabular}{lccccc}
\hline & \multicolumn{5}{c}{ Flaxility (sit-reaches) } \\
\cline { 2 - 6 } & $\mathrm{b}$ & $\beta$ & $\mathrm{t}$ & $P$ & $\mathrm{R}^{2}$ \\
\hline Somatization & -0.337 & -0.082 & -0.674 & 0.501 & -0.032 \\
Psychosis & 0.097 & 0.022 & 0.178 & 0.859 & \\
Paranoia & 0.213 & 0.040 & 0.419 & 0.676 & \\
Phobia & 0.166 & 0.029 & 0.254 & 0.800 & \\
Hostility & -0.366 & -0.142 & -0.841 & 0.401 & \\
Anxiety & -0.151 & -0.045 & -0.366 & 0.715 & \\
Depression & 0.030 & 0.015 & 0.086 & 0.931 & \\
Interpersonal sensibility & 0.224 & 0.069 & 0.576 & 0.565 & \\
Obsessive compulsive & 0.185 & 0.061 & 0.567 & 0.571 & \\
\hline & & & & &
\end{tabular}

session (Table 6), while flexibility (sit and reach) does not have influence mental health (Table 7). The degree of obesity (BMI) affects mental health but not the subdomains and shows a statistically significant difference (Table 8).

\section{DISCUSSION}

In this research, as a result of analyzing the mental health and health-related physical fitness of college students according to gender, not only did the female students have a lower level of fitness than male students but they also showed lower levels of mental health. Moreover, regarding the correlation between health-related physical fitness factors and mental health, it appears that physical fitness, muscle endurance, and cardiopulmonary endurance influence mental health, whereas flexibility does not. It is believed that this is because male students participate exercise frequently than female students. Furthermore, the higher the participation rate in regular exercise, the higher the health-related physical fitness level. Many studies have reported that regular exercise has an
Table 8. Relationship between BMI and mental health

\begin{tabular}{lccccc}
\hline & \multicolumn{5}{c}{ BMI } \\
\cline { 2 - 6 } & $\mathrm{b}$ & $\beta$ & $\mathrm{t}$ & $P$ & $\mathrm{R}^{2}$ \\
\hline Somatization & 0.201 & 0.249 & 2.14 & $0.033^{*}$ & 0.048 \\
Psychosis & -0.079 & -0.091 & -0.771 & 0.442 & \\
Paranoia & 0.082 & 0.079 & 0.868 & 0.387 & \\
Phobia & 0.208 & 0.187 & 1.70 & 0.089 & \\
Hostility & -0.138 & -0.275 & -1.70 & 0.090 & \\
Anxiety & -0.033 & -0.050 & -0.422 & 0.674 & \\
Depression & 0.007 & 0.016 & 0.101 & 0.919 & \\
Interpersonal sensibility & -0.142 & -0.222 & -1.95 & 0.052 & \\
Obsessive compulsive & -0.016 & -0.027 & -0.264 & 0.792 & \\
\hline
\end{tabular}

*Represents $P<0.05$.

effect on physical fitness and mental health (Han and Lee, 2006; Han et al., 2009; Jin, 2011). The university students' physical fitness levels influence metabolic syndrome (Kim et al., 2012; Regehr et al., 2013; Taylor et al., 2013) and body composition diagram; in other words, obesity affects self-esteem. This study showed that BMI, which predicts the degree of obesity, influences mental health. In a study with older patients as subjects, physical fitness factors such as muscular strength and muscle endurance affect depression and anxiety (Shin et al., 2004). Moreover, in a study of elementary students as subjects, physical fitness is significantly correlated with mental health (Choi, 2008; Hussian et al., 2013). These earlier studies showed the same results as those of our study. Therefore, the university students' physical fitness factors of muscular strength, muscle endurance, cardiopulmonary endurance, and degree of obesity affect mental health.

\section{CONCLUSIONS}

As a result of identifying the correlation between university students' health-related physical fitness and mental health, the following conclusion was reached in this study. First, a gender-related difference was seen on health-related physical fitness and mental health level. Second, the health-related physical fitness elements excluding flexibility - including cardiopulmonary endurance, muscular strength, muscle endurance, and degree of obesity - influence mental health.

\section{CONFLICT OF INTEREST}

No potential conflict of interest relevant to this article was reported. 


\section{ACKNOWLEDGMENTS}

This work was supported by Gachon University Grant (GCU2013-R399).

\section{REFERENCES}

Bolognini M, Plancherel B, Bettschart W, Halfon O. Self-esteem and mental health in early adolescence; development and gender differences. J Adolesc 1996;19:233-245.

Choi HG. Association of blood leptin level with cardiorespiratory fitness, body composition and metabolic syndrome in female collage students. Journal of Korean Physical Education Association for Girl and Women 2008;22:137-148.

Derogatis LR, Rickels K, Rock AF. The SCL-90 and the MMPI: a step in the validation of a new self-report scale. Br J Psychiatry 1976;128:280289.

Dubos KD, Eisenmann JC, Donnelly JE. Aerobic fitness attmuates the metabolic syndrome score in normal-weight at risk for overweight children. Pediatrics 2007;120:1262-1268

Han HW, Lee YC. The relationship among participation of dance sport, body image and mental health for university students. Journal of Korean Physical Education Association for Girl and Women 2006;20:109120

Han KL, Kim WS, Lim KS, Lim KY. The relationship between mental health, adjustment to collage and college students' sport activity. Journal of Sport and Leisure Studies 2009;35:1169-1178.

Hunt J, Eisenberg D. Mental health problem and help-seeking behavior among college students. J Adolesc Health 2010;46:3-10.

Hussian R, Guppy M, Robertson S, Temple E. Physical and mental health perspective of first year undergraduate rural university students. BMC
Public Health 2013;13:848.

Jin HM. The study of health promotion related life styles on university athletes and physical education students. Journal of Korean Physical Education Association for Girl and Women 2011;25(4):149-163.

Kim DI, Kim JY, Lee MK, Lee HD, Lee JW, Jeon J. The relationship between fitness, BMI and risk factors of metabolic syndrome among university students in Korea. Korea Society for the Study of Obesity 2012;21(2):99-107.

Labrie JW, Kenney SR, Lac A. The use of protective behavioral strategies is related to reduced risk in heavy drinking college students with poorer mental and physical health. J Drug Educ 2010;40:361-378.

LaMonte MJ, Barlow CE, Jurca R, Kampert JB, Church TS, Blair SN. Cardiorespiratory fitness is inversely associated with the incidence of metabolic syndrome: a prospective study of men and women. Circulation 2005;112:505-512.

Lee HG. A fact-finding survey and mental health of 1986' freshman. Yeonsei Council Study 1986;4(1):1-10

Moon HS. The relation of university students; sports participation to its physical self-concept stress and mental health. Journal of Sport and Leisure Studies 2008;32:1145-1158.

Regehr C, Glancy D, Pitts A. Interventions to reduce stress in university: a review and meta-analysis. J Affect Disord 2013;148:1-11.

Shin BC, Park JH, Kim HJ. The relationships between health related physical fitness and mental health in older adult. Korea Sports Research 2004;15:1735-1744.

Taylor D, Bramoweth A, Grieser E, Tatum J, Roane B. Epidemiology of insomnia in collage students: Relationship with mental health, quality of life, and substance use difficulties. Behav Ther 2013;44:339-348.

Zivin K, Eisenberg D, Gollust S, Golberstein E. Persistence of mental health problems and need in a college student population. J Affect Disord 2009;117:180-185. 